\title{
Estrategias micropolíticas: una mirada a la dirección escolar
}

\author{
Karina Edith Alva Aguilar \\ María de la Luz Jiménez Lozano \\ Universidad Pedagógica Nacional \\ Unidad Torreón
}

\section{Resumen}

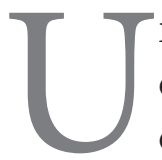

na mirada a la dirección escolar, desde la etnografía y las historias de vida, define el eje de esta investigación. La directora, como sujeto en la escuela, y sus relaciones en la acción directiva, están colocadas en el primer plano de la reconstrucción de la realidad social en un ámbito específico. ¿Qué acciones y conocimientos puede generar la experiencia personal y profesional de una maestra al constituirse en directora de escuela? Con esta pregunta derivada del interés por explorar cómo la vida de un individuo está conectada con historias colectivas y con los cambios estructurales del contexto en el que se inscriben, se traza una línea hacia la exploración de la vida de la directora, en el contexto profesional, personal y político, a través de las estrategias desplegadas para dirigir una escuela.
Palabras clave: sujeto, experiencia, acción directiva, micropolítica, gestión escolar

\section{Ser directora: construirse en la expe- riencia}

La investigación produjo una historia que fue reconstruida siguiendo las narrativas de Lucía -directora de una escuela primaria pública- $\mathrm{y}$ de algunos profesores que han trabajado con ella. Integra explicaciones e interpretaciones realizadas en las relaciones micropolíticas. A través de entrevistas abiertas, Lucía comparte cuándo y cómo llegó a ser directora. Señala los problemas que ha enfrentado, las maneras en que ha buscado su profesionalización, así como las estrategias para cultivar la relación con maestros y padres de familia para lograr que sea una "buena escuela". Los profesores -por su parte- ofrecieron sus propias versiones. El análisis empírico fue dirigido en torno a los saberes y las 
valoraciones sobre la escuela, que configuran a la Directora como agente clave en la micropolítica escolar y la relación con las pautas discursivas de un proyecto que atraviesa la vida profesional e institucional: los discursos que sostienen las propuestas de una nueva gestión para la escuela pública.

La reconstrucción de la vida cotidiana de la escuela (Rockwell, 2009) y los relatos biográficos de una directora (Delory, 2009) desde una posición política, no solo permiten representar la trayectoria profesional, sino también producen una narración diacrónica de las acciones más significativas en la constitución de sí y de la escuela que dirige (Foucault, 1981).

Cada experiencia, cada cruce de la trayectoria personal con la trayectoria laboral y los contextos de realización, configuran la acción directiva y contribuyen a significar los modelos de gestión construidos en esos itinerarios.

Cada relato nos permite situar la constitución subjetiva como producto de las relaciones socio-históricas en las que se configuran las tramas que se tejen en la escuela, especialmente las relaciones entre directora, maestros y padres de familia que fueron ampliamente documentados en el informe final.

El propósito de este texto es ofrecer algunas imágenes que dejan ver la posición y las relaciones en la constitución como directora. Se trata de acotamientos en la trayectoria laboral y personal que dan lugar a ciertas racionalidades y formas de hacer que sustentan su participación directiva $y$ el modelo de gestión que promueve.

\section{Llegar a la Dirección de una escuela}

La vida profesional de un docente está marcada por acontecimientos que no siempre representan el fin de una intervención estratégica. En el trayecto profesional que posibilita llegar a ocupar la dirección de una escuela, cuenta la antigüedad en la zona o los puntos escalafonarios (Sandoval, 1986). Ocupar una dirección conlleva cambios en el actuar, ya que se deja el aula, a los niños y la enseñanza formal, para ubicarse en ese espacio micropolítico, que supone un sistema de relaciones más complejo, retos, conflictos y situaciones desafiantes implícitas en la consigna-fin de dirigir una escuela.

En esta investigación, la acción directiva fue analizada en dos perspectivas: desde lo macroinstitucional, explorando el potencial productivo de los discursos de políticas educativas (Foucault, 1981; Popkewitz, 1994); y en una mirada micropolítica (Ball, 1989) desde la cual se analizaron los sucesos y prácticas de los actores en el espacio escolar. Se parte de cuestionar los sentidos que imprime la definición de una figura institucional reconocida como indispensable para la gestión y logro de metas educativas encaminadas a mejorar la calidad de educación en el país. El liderazgo directivo, se integra como componente de la nueva gestión de la escuela pública, sostenida como línea de política, en las reformas de las últimas dos décadas ¿pero qué ocurre en las escuelas?

El énfasis en definir a los directores como líderes, se relaciona con el proceso de llegar a ser directora, porque la autorización es la que confiere nombramiento

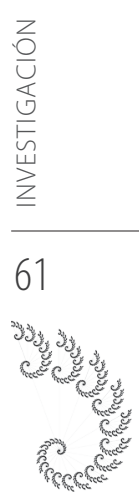


de manera oficial y de manera legal, pero la capacidad de dirigir, la autoridad en los procesos institucionales, es decir, ser director o directora, se construye día a día, se gana en las relaciones y estrategias desplegadas en el campo.

En el contexto escolar casi la totalidad de los directivos del nivel de educación básica acceden al cargo después de haberse desempeñado como docentes durante varios años. Así, la experiencia docente constituye el elemento más significativo que acompaña al director/a en el momento que asume el encargo institucional.

A Lucía, esta experiencia la ha llevado a construir una visión sobre la organización de la escuela y de las formas específicas en las que se establece la relación con agentes internos y externos de la comunidad escolar: "Tengo 33 años de servicio, he trabajado en esta escuela 25 años y desde hace seis años, soy directora. Primero fui subdirectora por un año y medio y después se jubiló la directora y yo pasé a ser directora" (R102-05).

Luego de su nombramiento como directora Lucía decidió estudiar,"prepararse para asumir" el puesto. Se adscribió a los discursos de las propuestas gubernamentales que promovían la formación de directivos como agentes fundamentales del cambio.

El quiebre significativo en la trayectoria profesional que representó llegar a ser directora, la llevó a buscar "la profesionalización”, desde su convicción de que se requieren competencias profesionales diferentes de las de un docente. Desplegó una gran actividad formativa, su historia se vincula con los proyectos institucionales. Estaba concluyendo estudios de Licenciatura y se vio impelida a participar en cursos de actualización y diplomados. Uno de los más valorados es el del Programa Escuelas de Calidad del cual destaca la revisión de materiales bibliográficos que recomiendan las relaciones entre la escuela y los padres de familia, a partir de los cuales fue desplazando su postura como maestra, negada a la intervención de los padres:

Yo estuve primero en la licenciatura (en la Universidad Pedagógica Nacional) y los textos que leí me abrieron la mente, porque yo (...) era una de las maestras que no aceptaba que el padre entrara (...) a mi salón. Después tomé los diplomados para directivos. Esos me han cambiado personal y profesionalmente. Aprendí a involucrar a los padres de familia dentro de la escuela. Hemos tenido muchos problemas en el pasado desde que yo era maestra, pero todo esto ha cambiado (...) ellos ayudan bastante, cuando se les da oportunidad... (R 1 EDIR2).

El discurso educativo actual la ha sensibilizado, su visión como maestra y los cambios que se han producido al llegar a ser directora, le permiten valorar la experiencia de su preparación profesional en espacios institucionales y se adscribe a los discursos sobre la gestión como base para decidir lo que puede realizar en la escuela y para el mejoramiento de la calidad escolar. Es enfática al referirse a la vinculación de la directora y padres de familia como agentes clave. Defiende su interés por encauzar el funcionamiento del plantel a su cargo, definiendo las metas, estrategias y políticas que busca implementar, involucrando a los padres de familia. 
Si consideramos que la gestión escolar, remite al gobierno de la escuela, la dinámica producida para legitimar o restringir la participación de los docentes y padres de familia, va cobrando forma en la trama de relaciones que la acción directiva fomenta e impulsa. En el caso de Lucía: "el perfeccionamiento de los directores no se produce de manera esencial; a través de prescripciones, de teorías, de cursos, de reglas que le trasmiten personas que están fuera del contexto escolar" (Santos Guerra, 1994: 172) sino en las relaciones micropolíticas que hacen posible que sus estrategias definan el campo de acción para los demás.

La oportunidad de moldear su estilo y estrategias de gestión, de construir un perfil como protagonista del contexto escolar o ser parte solo del paisaje institucional radica en la manera en cómo aparecen las imágenes de lo que le significa la escuela y de sí misma como directivo, cada imagen la constituye como agente social y político dentro del contexto escolar:

La escuela para mí... es lo máximo, lo que siento es que es una gran responsabilidad y como un reto a ser competitiva con la escuela privada. En todos los ámbitos: busco que no sea una escuela común y corriente, que sea de calidad (RI22-05-07).

Se asume a sí misma como elemento clave en un proceso de búsqueda de la calidad educativa, de la competitividad entre la escuela pública y la privada, será insistente en señalar que si la dirección de la escuela no está involucrada y comprometida con los requerimientos actuales de la sociedad, difícilmente mejorará la calidad de la educación. Su imagen como directora la ubica como responsable, mediadora entre el currículo y las exigencias que van destinadas a los maestros dentro de la escuela.

La forma de pensar sobre la tarea educativa, las funciones de la escuela y las normas a las que está sujeto el ejercicio de la acción directiva, las expresa vinculando su condición profesional, laboral y personal:

Ser directora para mí es responsabilidad... porque me toca administrar recursos humanos, sacar la cara por todos. Y sacar de cada uno lo mejor. Si no lo hacen, a lo mejor hay que enseñarles, y eso también es parte de mi trabajo. Cuando uno quiere su trabajo lo disfruta. Pero además, es más fácil cuando delego autoridad, es menos pesada la carga, y agrégale que te pagan por lo que te gusta, ¿qué más quieres? (R222-05).

A la posición que ocupa formalmente atribuye el valor de la responsabilidad y "eficientar" la administración, términos relacionados con los discursos sobre la gestión educativa. En un primer plano, se ve a sí misma como responsable del centro escolar; da la cara por todos, supone la autorización para tomar decisiones que muchas veces no son aprobadas por todos los docentes, pero como líder, siguiendo el discurso administrativo, es ella quien decide cuándo y cómo delegar, y en quién o quiénes.

Recién nombrada, algunas de sus decisiones como directora transgredieron elementos ya sedimentados en la cultura escolar, de la cual era parte, pero en su nueva posición se requiere tener una mirada distinta:

Los primeros problemas fueron con la sociedad de padres de familia; no 
REVISTA DE INVESTIGACIÓN EDUCATIVA DE LA REDIECH N. 9 ISSN: 2007-4336

eran mis problemas, pero yo los recibí. Problemas de organización y económicos. Con la cultura en padres de familia y alumnos, con los maestros, las inasistencias, llegadas tarde, no había respeto entre ellos, de organización de trabajo con los maestros, no estaban actualizados en muchas cosas, no planeaban, confundían contenidos con actividades y no se les exigía que planearan (R302-05).

Se enfrentaba a "problemas heredados", presentes antes de asumir la dirección, sobre los que ahora sí podría realizar incidir. Estratégicamente, el discurso de la directora opera más en un plano institucional, básicamente administrativo, de gestión de recursos y de control de intereses, para garantizar lo que se concibe como el apego a la normatividad: se refiere a las situaciones en la que el director se respalda, decide o limita a los otros, bajo las condiciones establecidas en un documento oficial y que su acción queda acotada por éste, “... les voy a pedir, no lo que yo indique, sino lo que indica el programa: $\mathrm{Y}$ es que estemos nosotros, 10 minutos antes de la hora" (R 20 OR-26-02).

La dinámica particular adopta distintas formas y el ejercicio del poder se produce en distintos niveles. Se caracteriza por establecer relaciones móviles, inestables, modificables y que se pueden invertir. Vemos la imagen, en el momento en que la directora quiere seguir los lineamientos del sistema educativo desde el inicio del ciclo escolar y a través de la investidura, busca limitar la acción de los docentes y padres de familia:

... al inicio escolar, leo el reglamento del director, para que sepan ellos cuáles son mis obligaciones, yo no tengo miedo de decirles cuáles son mis obligaciones, también leo el reglamento interno de la escuela, se lo leo a los padres, a los maestros, les leo los aspectos que ameritan un acta administrativa, si no conocemos la normatividad, podemos cometer muchos errores... (R2618-05).

La directora se erige como autoridad máxima y desde esa posición impone al resto de la comunidad la obligación de atender normas y ordenamientos. En la micropolítica se controla la acción de los demás, puede ser analizada como estrategia de poder utilizada para tomar ventaja sobre los padres de familia. Un juego que se origina al decir lo que piensa y lo que posiblemente hará en caso de alterar o no cumplir con lo establecido. Sus acciones están justificadas en un reglamento al cual alude, tratando de jugar con el poder que éste le confiere. La directora se convierte en una ejecutora y vigilante de la ejecución de lo prescrito, dejando en claro qué se puede hacer y qué no. Como ella misma lo comenta “... los nuevos (padres) tienen que respetar las normas que tenemos aquí, el reglamento, porque antes de inscribir tienen que firmar un reglamento... (R1602-02).

En este juego micropolítico, el uso de técnicas de administración implica la importación a la escuela de procedimientos de control organizativo gerencialistas ${ }^{1}$. El lugar de la directora se rige por los preceptos y procedimientos que constituyen la administración y que toma al pie de la letra, ya del manual de funciones, ya de la propuesta de gestión de la calidad. Al leerles a los maestros, padres y alumnos el reglamento, quedan fijadas y formalizadas públicamente las posiciones y responsabi- 
lidades del personal a su cargo y las responsabilidades de los padres para el funcionamiento de la escuela, “.... los padres, les leo el reglamento de la asociación de padres de familia, ¡maestros!, ese reglamento hay que tenerlo en las manos, para marcarles hasta donde pueden intervenir ellos y en donde no..." (R7 29-08).

Estas formas de relación, de marcar límites, van configurando un modelo de gestión con relaciones asimétricas, en donde los actores no están en igualdad de condiciones con respecto a quiénes proponen y deciden, respecto de quienes han de asumir propuestas y decisiones. En el caso específico, la Directora establece límites de acción para los demás, respaldándose en los reglamentos. Se trata de una gestión que responde a un acto, donde el poder es un modo de acción, de directividad coercitiva.

La directora es el eje de gestión, la normatividad, el reglamento, los programas, se relacionan con lo que Ezpeleta (2000) señala como "el sentido y prioridades del quehacer de los directores", en este caso, cumplir encargos institucionales para lo cual es preciso controlar o tratar de disciplinar a los otros.

Las prácticas que lleva a cabo la directora y que la definen y distinguen de otros directores, se reconstruye cuando se le cuestiona acerca de los cambios que ha tenido como directora y cómo le ha hecho para llegar a ser quien es. Como directora ha tenido que cambiar "estrategias de organización para el trabajo y comunicación”, buscar estrategias que le permitan "hacer que los docentes realicen algo, aún en contra de su voluntad". Los mecanismos, modalidades de ejercicio o instrumentos que configuran el ejercicio del poder, aparecen junto con la realización de otras actividades: asesoría en talleres, proyección de temas motivacionales, orientación y supervisión incluidos en las agendas institucionales.

Las estrategias micropolíticas de la directora representan el arte de dirigir las tareas organizativas exigidas por los ordenamientos externos e institucionales. Se plantean como estrategias micropolíticas aquellos mecanismos que conllevan intereses personales y/o ideológicos dentro de la institución, se trata de las estrategias o tácticas de la directora que suponen un conocimiento y una intervención en la estructura de la perspectiva política de la escuela.

¿Cómo le he hecho? pues como directora, el PEC, elevar mi nivel académico. Yo personalmente diseño los talleres, porque he visto la necesidad que hay en mi escuela. Entre todos diseñamos el Programa Anual de Trabajo. Ya no estamos en PEC, pero no queremos retroceder, si ya teníamos esa cultura tenemos que seguir con ella para poder hacer las cosas bien... (R26-01-02).

La declaración remite a una imagen de sí misma, en la que se sitúa metafóricamente, como estratega en el actuar directivo, que tiene que reunir todo lo que sabe para enfrentar acontecimientos en los que sitúa a los otros en condición de aprendices; confiada en la experiencia como maestra de grupo y su prolongada estancia en la escuela: “... esto a mí me ha enseñado PEC, todos los diplomados que ha organizado PEC, ahí estoy, todos los talleres que organiza PEC, ahí estoy, porque tengo que con- 
jugar mi experiencia con el conocimiento (R 26-18-05).

La forma de actuar, la gestión concebida como gobierno de los otros ${ }^{2}$, visibiliza la posición frente a las disposiciones externas, al definirse como autoridad preparada y capacitada para asumir la responsabilidad de instruir a los docentes. En su discurso, alude cómo un proyecto, el de Escuelas de Calidad, le ha permitido aprender a dirigir una escuela.

\section{Estrategias pedagógicas: “... los maestros de mi escuela planean...”}

Otro vínculo importante por analizar está representado por las técnicas y prácticas a través de las cuales los individuos se moldean activamente al ocuparse de sí y de los otros (Foucault, 1988), y que los hacen aptos para actuar tanto en el plano individual como en el plano político y social, tal y como la directora busca ordenar y capacitar a los maestros a través de talleres que ella diseña e imparte a nivel escuela y a nivel de zona escolar.

Diversos acontecimientos son aprovechados por la directora para cuidar del centro escolar a su cargo. Vemos como el acontecer cotidiano de la escuela abre la posibilidad de construir varias estrategias de vigilancia pedagógica. Estas estrategias, que pueden ser calificadas de controladoras y unipersonales e incluso informales, sobresalen en las reuniones con los profesores. Constantemente expresa su preocupación de que se cumpla con la enseñanza, la dosificación de contenidos, la planeación, en suma, las tareas inherentes a la organización de trabajo en el aula, “... tengo que insistir que hay que planear las actividades y saber muy bien el propósito de cada actividad. Desde que llegue aquí me he dedicado a enseñar a planear las actividades para lograr mejores resultados... (R 3-05-01).

A partir de dicha declaración, vale señalar la manera en que la directora actúa para gobernar a los otros, pues gobernar no solo cubre las formas legítimamente constituidas de sujeción política o económica, sino también modalidades de acción más o menos consideradas y calculadas, orientadas a actuar sobre las posibilidades de los otros (Foucault, 1981) en este caso los docentes, a quienes hay que enseñar y capacitar.

Desde la perspectiva de la dirección, la planeación se convierte simultáneamente en un crisol que hace visible la competencia profesional de un docente, quien al planear y dosificar adecuadamente los contenidos, logrará obtener mejores resultados académicos. Se hace presente la investidura institucional en cada episodio en el que acciones o resultados difieren de los esperados directivamente. Reúne a los maestros y señala debilidades pedagógicas, en una dinámica en la que también tiene que ver la manera en que los otros, en este caso los docentes, asumen su posición. Hay una directividad legitimada en la asimetría de las relaciones, donde la subordinación de los maestros ante los ordenamientos y juicios de la directora, opera como aceptación.

La planeación que los maestros deben entregar cada semana, se convierte en un mecanismo de control interno, expresado en negociaciones y pláticas de "concientización", señalamiento o reconocimiento público: 
Yo les había dicho que la planeación me la entregaran los lunes, a la salida; y muchos de ustedes, no me la están entregando; algunos de ustedes no me han entregado, $y$ a otros no les firmo, porque no me queda claro lo que van a hacer, no concuerda el contenido con la actividad y les voy a encargar por favor, que los que tengan dudas, pasen a la dirección a la hora de educación física, o cuando tengan inglés, previa cita, porque a veces estoy ocupada, vamos a utilizar algunas horas libres que tenemos de preferencia educación física y para cualquier duda estoy en la tarde, de dos a seis y media en la supervisión, también ahí los puedo atender porque soy asesora y les voy a pedir de favor que me digan a quien le hace falta el cuadernillo de planeación, para inmediatamente hacérselos, ¿a nadie le hace falta el cuadernillo? ( $\mathrm{R}$ 20 09-10).

Un elemento adicional que sugiere la información analizada es que la estrategia de vigilancia pedagógica muestra los medios empleados para la consecución de un cierto fin, es por lo tanto una cuestión de racionalidad orientada a un objetivo, en este caso, lograr mejores resultados en las evaluaciones externas. Alcanzarlos, implica supervisar el trabajo docente y estar vigilando que se realice según lo establecido. En este espacio, el eje de la gestión, consiste en generar estrategias, perfilar acciones y otorgar prioridades a la actividad docente. Posición que le obliga a idear estrategias "novedosas", encaminadas a mejorar el aprendizaje de los alumnos expresados en los resultados de los exámenes.

Con este taller yo concluí, que es importante la planeación, el maestro que no hace una planeación, está totalmente perdido, si nosotros no sabemos planear no vamos nunca a pasar un examen, entonces, vamos a analizar los reactivos de las pruebas de ENLACE, de la Olimpiada, los exámenes bimestrales (R 8 08-04).

Al realizar el cruce de los discursos, permite hacer un análisis y contrastar la realidad, cotidianamente, les dice a los maestros que no le están entregando la planeación, o que no le gusta o no le queda claro lo que los maestros escriben en sus planeaciones, razón por la cual, no las firma o autoriza. Como directora, ellos no cumplen con los criterios que establece; a los maestros les falta, como dijera una de las maestras que "...ella (la directora) dice, ique nos falta 'chispa', que somos muy aburridos!, pero ¿qué es que nos falte chispa, si trabajamos como ella quiere, no faltamos y tratamos bien a los niños, qué más quiere" (NC 0410). En la misma dirección, la maestra MREB dice:“...piensa que no sabemos, nos ve como niños a los que tiene que enseñar todo, y no es así, lo que pasa es que quiere que hagamos lo que ella dice y nada más" (NC 04-10).

Frente a las oposiciones, ella facilita los medios con los cuales tendrá a los docentes sujetos a una dinámica de cumplimiento, de aquello que como directora, considera pertinente para lograr mejores resultados en las aulas. Así que, el interés por la planeación de las actividades aparece en el discurso directivo con la intención de, no solo transformar prácticas arraigadas de enseñanza que tienen algunos maestros, como la constante improvisación dentro del aula y "al mal hábito" de no planear. El modelo directivo está orientado hacia la 
asesoría pedagógica de los profesores. A su vez, aludiendo a los lineamientos de la reforma educativa, demanda colocar como prioridad de la acción de todos los profesores y directivos, el mejoramiento de los logros educativos, especialmente los relacionados con los propósitos básicos, a saber: el desarrollo de habilidades intelectuales, la adquisición de conocimientos fundamentales y la formación de valores y actitudes. Consecuentemente, la planeación es un instrumento de control y poder directivo que origina algunas veces conflictos entre las ideas de los maestros quienes ven amenazada su autonomía y es expresión de resistencia, “...es que yo he visto que en otras escuelas, dan libertad para planear, es la primera vez que veo lo que se hace aquí en esta escuela..." (R 8 09-04).

El modelo de gestión reconstruido en la posición de autoridad le confiere la necesidad de orientar, supervisar, disciplinar, educar a los profesores y a los padres de familia. Para ella, la escuela y la dirección constituyen un Yo, es decir, todo gira alrededor de su posición de autoridad y modo de gobierno. Frente a lo cual cabe afirmar que:

La percepción que cada director tiene sobre la autonomía de la escuela y la manera en que ésta se ejerce, también son importantes para determinar el sentido de sus acciones, el tipo de relaciones que se establecen y la forma en que estas relaciones limitan o no su libertad para generar, como escuela, estrategias novedosas, encaminadas a mejorar el aprendizaje de los alumnos (Furlán, et.al, 2000).

Aquí, entre la vigilancia del cumplimiento de los reglamentos y la conducción de la tarea pedagógica, se instala una dirección asumida como proyecto de escuela y de realización personal.

\section{Notas}

1. El modelo adoptado será reiterativamente expresado: el modelo de gestión estratégica de Escuelas de Calidad. Las alusiones a la mejora de la escuela, a la colaboración del colectivo escolar, a la conjunción de esfuerzos y un liderazgo con claridad de metas (SEP, 2007)

2. A partir de los planteamientos foucalteanos se puede analizar el discurso directivo ya que dicha postura se interesa en la manera en que los sujetos se constituyen, se moldean a sí mismos mediante prácticas y técnicas que ejercen sobre sí y que, no obstante, no son inventadas por ellos, sino que son esquemas de percepción y de actuación que les son impuestos por su cultura, su sociedad, su grupo social (Foucault, 1988).

\section{Bibliografía}

Ball, S. (1989). La micropolítica de la escuela. Hacia una teoría de la organización escolar. Paidós. Barcelona.

Delory-Momberger, C. (2009). Biografía y Educación. Figuras del Individuo-proyecto. Buenos Aires: CLAC$\mathrm{SO}$

Ezpeleta, J. y Furlan, A. (Comp.) (2000). La gestión pedagógica de la escuela. México: Correo de la Unesco -UNESCO.

Foucault, M. (1981). La gubernamentalidad en espacio de poder. La Piqueta: Madrid.

Foucault, M. (1988). El sujeto y el poder. Revista Mexicana de Sociología. Vol. 50, No. 3, jul-sept, pp.3-20

Furlán, A., et al. (2000). La gestión pedagógica. Polémicas y casos. La gestión pedagógica de la escuela. México: Correo de la UNESCO-UNESCO.

Popkewitz, S. Th. (1994). Sociología política de las reformas educativas. Madrid: Morata.

Rockwell, E. (2009). La experiencia etnográfica. Historia y cultura en los procesos educativos. Buenos Aires: Paidós.

Sandoval, E. (1986). Los maestros y su sindicato. Departamento de Investigaciones Educativas, Centro de Investigación y de Estudios Avanzados del I.P.N. p. 210.

Santos Guerra, M. A. (1994). Entre bastidores. El lado oculto de la organización escolar. Ed. Aljibe: Archidona.

SEP (2007). Plan estratégico de transformación escolar. México. 